\title{
Compensation for Rotor Position Estimation Error due to Cross-Coupling Magnetic Saturation in Signal Injection Based Sensorless Control of PM Brushless AC Motors
}

\author{
Z. Q. Zhu, Y. Li, D. Howe, and C. M. Bingham \\ Department of Electronic and Electrical Engineering, University of Sheffield, Mappin St., Sheffield S1 3JD, UK
}

\begin{abstract}
This paper proposes a simple method for reducing the rotor position estimation error caused by cross-coupling magnetic saturation between the $d$ - and $q$-axes when signal injection based sensorless control is applied to a brushless AC (BLAC) motor. The error in the estimated rotor position, which results when conventional signal injection sensorless control is employed, is analyzed. Based on an improved model of a BLAC motor which accounts for the influence of $d q$-axis cross-coupling on the high-frequency components of the incremental winding inductances, as deduced by either finite element analysis or from measurements, an improved signal injection based sensorless scheme is proposed. Its effectiveness is demonstrated by measurements on a BLAC motor having an interior permanent magnet rotor.
\end{abstract}

\section{INTRODUCTION}

It is necessary to acquire rotor position information for a permanent magnet (PM) brushless AC (BLAC) motor in order to control the 3-phase stator currents, and, hence, the torque. Generally, either an encoder or a resolver is employed. However, such discrete position sensors not only increase the system complexity and cost, but may also compromise the reliability. It is desirable, therefore, to estimate the rotor position indirectly from the terminal voltages and currents.

Sensorless methods based on high frequency signal injection exhibit excellent rotor position estimation performance at standstill and low speeds, when back-EMF based sensorless methods are problematic. The most common high frequency signal injection method uses a sinusoidal carrier voltage signal. It was originally developed for use with induction motors, but was subsequently applied to PM BLAC motors with geometric saliency [1-5]. The identification of the initial rotor position was obtained in [4] [5] by comparing sine and cosine terms in the $2^{\text {nd }}$-order harmonic component in the $d$-axis current. In [6], it was applied to a non-salient BLAC motor equipped with a surface-mounted PM rotor, by utilizing the saliency effect which was caused by magnetic saturation.

However, it was found experimentally in [2] that the error in the estimated rotor position increases with the load current, although the problem was not fully studied or solved. Recently, it was established in [7] [8] that the error was caused by the effect of cross-coupling magnetic saturation between the $d$ - and $q$ - axes, (i.e., $L_{d q h} \neq 0$ ), and was influenced by the machine design, but, as yet, no measures, from the control aspect, have been proposed to reduce the error. Nevertheless, it is well known that a mutual inductance exists between the $d$ - and $q$ axes of a BLAC motor $\left(L_{d q h}\right)$ as a result of cross-coupling due to magnetic saturation, as shown in [9], both experimentally and by finite element analysis. However, for simplicity, the influence of cross-coupling magnetic saturation is usually neglected in sensorless rotor position control [1-6].

This paper improves the rotor position estimation accuracy in a signal injection based sensorless control scheme by accounting for the influence of cross-coupling due to magnetic saturation. Section II presents an improved model of a BLAC motor which accounts for the influence of the cross-coupling. Section III analyzes the position estimation error which arises when cross-coupling is neglected, and proposes a simple method of reducing the error, based on either predicted or measured incremental inductance characteristics. Measurements are presented in section IV which validate the effectiveness of the proposed method.

\section{Analysis of Cross-Coupling Effect in Brushless AC MOTOR}

For a 3-phase BLAC motor, the phase voltages, $v_{a}, v_{b}$, and $v_{c}$ are given by:

$$
\left[\begin{array}{l}
v_{a} \\
v_{b} \\
v_{c}
\end{array}\right]=R_{s}\left[\begin{array}{l}
i_{a} \\
i_{b} \\
i_{c}
\end{array}\right]+\left[\begin{array}{l}
d \psi_{a} / d t \\
d \psi_{b} / d t \\
d \psi_{c} / d t
\end{array}\right]
$$

where $i_{a}, i_{b}, i_{c}, \psi_{a}, \psi_{b}$ and $\psi_{c}$ are the phase currents and flux-linkages, respectively, and $R_{s}$ is the stator winding phase resistance. Since the 3-phase flux-linkages are functions of the phase currents and the rotor position, $\theta_{r},(1)$ can be expressed as: 


$$
\begin{aligned}
& {\left[\begin{array}{l}
v_{a} \\
v_{b} \\
v_{c}
\end{array}\right]=R_{s}\left[\begin{array}{l}
i_{a} \\
i_{b} \\
i_{c}
\end{array}\right]+\left[\begin{array}{lll}
\frac{\partial \psi_{a}}{\partial i_{a}} & \frac{\partial \psi_{a}}{\partial i_{b}} & \frac{\partial \psi_{a}}{\partial i_{c}} \\
\frac{\partial \psi_{b}}{\partial i_{a}} & \frac{\partial \psi_{b}}{\partial i_{b}} & \frac{\partial \psi_{b}}{\partial i_{c}} \\
\frac{\partial \psi_{c}}{\partial i_{a}} & \frac{\partial \psi_{c}}{\partial i_{b}} & \frac{\partial \psi_{c}}{\partial i_{c}}
\end{array}\right]\left[\begin{array}{l}
\frac{d i_{a}}{d t} \\
\frac{d i_{b}}{d t} \\
\frac{d i_{c}}{d t}
\end{array}\right]+\left[\begin{array}{l}
\frac{\partial \psi_{a}}{\partial \theta_{a}} \frac{d \theta_{a}}{d t} \\
\frac{\partial \psi_{b}}{\partial \theta_{b}} \frac{d \theta_{b}}{d t} \\
\frac{\partial \psi_{c}}{\partial \theta_{c}} \frac{d \theta_{c}}{d t}
\end{array}\right]} \\
& =R_{s}\left[\begin{array}{l}
i_{a} \\
i_{b} \\
i_{c}
\end{array}\right]+\left[\begin{array}{lll}
L_{a h} & L_{a b h} & L_{a c h} \\
L_{b a h} & L_{b h} & L_{b c h} \\
L_{c a h} & L_{c b h} & L_{c h}
\end{array}\right] p\left[\begin{array}{l}
i_{a} \\
i_{b} \\
i_{c}
\end{array}\right]+\omega_{r}\left[\begin{array}{l}
-E_{s}\left(\theta_{a}\right) \\
-E_{s}\left(\theta_{b}\right) \\
-E_{s}\left(\theta_{c}\right)
\end{array}\right]
\end{aligned}
$$

where $L_{a h}, L_{b h}$, and $L_{c h}$, and $L_{a b h}, L_{b c h}, L_{c a h}, L_{b a h}, L_{c b h}$, and $L_{a c h}$ are the phase incremental self-inductances and incremental mutual-inductances, respectively. $\theta_{a} \theta_{b}$, and $\theta_{c}$ are the position of the phase windings relative to the rotor, and defined as: $\theta_{a}=\theta_{r}$, $\theta_{b}=\theta_{r}-2 \pi / 3$, and $\theta_{c}=\theta_{r}+2 \pi / 3$, and $E_{s}$ is the phase EMF. In a signal injection based sensorless control scheme, only the high frequency terms in (2) are considered [6], i.e.:

$$
\left[\begin{array}{l}
v_{a h} \\
v_{b h} \\
v_{c h}
\end{array}\right]=\left[\begin{array}{lll}
L_{a h} & L_{a b h} & L_{a c h} \\
L_{b a h} & L_{b h} & L_{b c h} \\
L_{c a h} & L_{c b h} & L_{c h}
\end{array}\right] p\left[\begin{array}{c}
i_{a h} \\
i_{b h} \\
i_{c h}
\end{array}\right]
$$

where $v_{a h}, v_{b h}$, and $v_{c h}$, and $i_{a h}, i_{b h}$, and $i_{c h}$ are the high frequency components of the phase voltages and currents, respectively, and $p=d / d t$. Equation (3) can be transformed into the $d q$-axis reference frame as:

$$
\begin{aligned}
{\left[\begin{array}{c}
v_{d h} \\
v_{q h} \\
*
\end{array}\right] } & =C^{-1}\left[\begin{array}{ccc}
L_{a h} & L_{a b h} & L_{a c h} \\
L_{b a h} & L_{b h} & L_{b c h} \\
L_{c a h} & L_{c b h} & L_{c h}
\end{array}\right] C \cdot p\left[\begin{array}{c}
i_{d h} \\
i_{q h} \\
0
\end{array}\right] \\
& =\left[\begin{array}{ccc}
L_{d h} & L_{d q h} & * \\
L_{q d h} & L_{q h} & * \\
* & * & *
\end{array}\right] \cdot p\left[\begin{array}{c}
i_{d h} \\
i_{q h} \\
0
\end{array}\right]
\end{aligned}
$$

where $C$ is the 'Park' transformation matrix, and $L_{d h}, L_{q h}, L_{d q h}$ and $L_{q d h}$ are the $d$ - and $q$-axis incremental self- and mutualinductances, i.e.:

$C=\left[\begin{array}{ccc}\cos \theta_{a} & -\sin \theta_{a} & 1 \\ \cos \theta_{b} & -\sin \theta_{b} & 1 \\ \cos \theta_{c} & -\sin \theta_{c} & 1\end{array}\right]$

$$
\left[\begin{array}{ccc}
L_{d h} & L_{d q h} & * \\
L_{q d h} & L_{q h} & * \\
* & * & *
\end{array}\right]=C^{-1}\left[\begin{array}{ccc}
L_{a h} & L_{a b h} & L_{a c h} \\
L_{b a h} & L_{b h} & L_{b c h} \\
L_{c a h} & L_{c b h} & L_{c h}
\end{array}\right] C
$$

$L_{a h}$ and $L_{a b h}$ can be determined according to the definitions which are given in (7), while the phase flux-linkages can be calculated by finite element analysis by imposing the appropriate 3-phase currents.

$$
\left\{\begin{array}{l}
L_{a h}=\left[\psi_{a}\left(i_{a}+\Delta i, i_{b}, i_{c}, \Phi_{m}\right)-\psi_{a}\left(i_{a}, i_{b}, i_{c}, \Phi_{m}\right)\right] / \Delta i \\
L_{a b h}=\left[\psi_{a}\left(i_{a}, i_{b}+\Delta i, i_{c}, \Phi_{m}\right)-\psi_{a}\left(i_{a}, i_{b}, i_{c}, \Phi_{m}\right)\right] / \Delta i
\end{array}\right.
$$

where $\Delta i$ is an incremental current, and the influence of the permanent magnet flux, $\Phi_{m}$, on the magnetic saturation is considered in the finite element calculation of $\psi_{a}$.

Since the incremental phase self- and mutual-inductances are functions of the rotor position, $\theta_{r}$, the terms in the incremental inductance matrix are given by:

$\left\{\begin{array}{l}L_{a h}=L_{a h}\left(\theta_{r}\right) \\ L_{b h}=L_{a h}\left(\theta_{r}-2 \pi / 3\right), \\ L_{c h}=L_{a h}\left(\theta_{r}+2 \pi / 3\right)\end{array}\left\{\begin{array}{l}L_{a b h}=L_{b a h}=L_{a b h}\left(\theta_{r}-\pi / 3\right) \\ L_{b c h}=L_{c b h}=L_{a b h}\left(\theta_{r}-\pi\right) \\ L_{c a h}=L_{a c h}=L_{a b h}\left(\theta_{r}+\pi / 3\right)\end{array}\right.\right.$

The $d$ - and $q$-axis incremental self- and mutual-inductances may be determined approximately from the phase inductances using (6). By way of example, typical finite element calculated magnetic field distributions on both open-circuit and at rated load for the machine under consideration are shown in Fig. 1, and corresponding phase incremental self- and mutual-inductances, $L_{a h}$ and $L_{a b h}$, and $d$ - and $q$-axis incremental self- and mutual-inductances, $L_{d h}, L_{q h}, L_{d q h}$, and $L_{q d h}$, are shown in Figs. 2 and 3, respectively. The direct calculation of $d$ - and $q$-axis incremental self- and mutual- inductances will be discussed later.

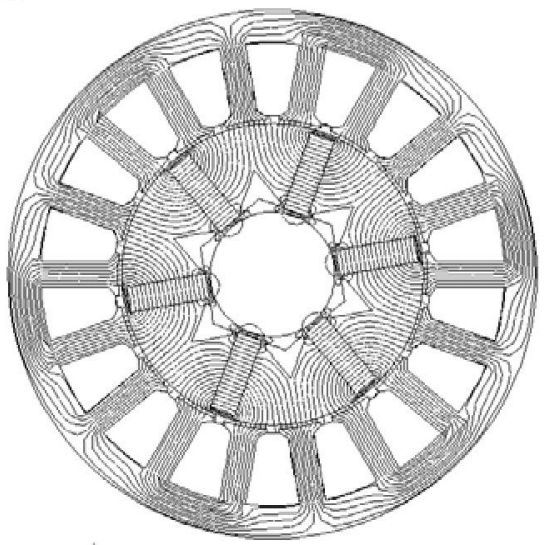

(a) Open circuit, $i_{d}=0 \mathrm{~A}, i_{q}=0 \mathrm{~A}$.

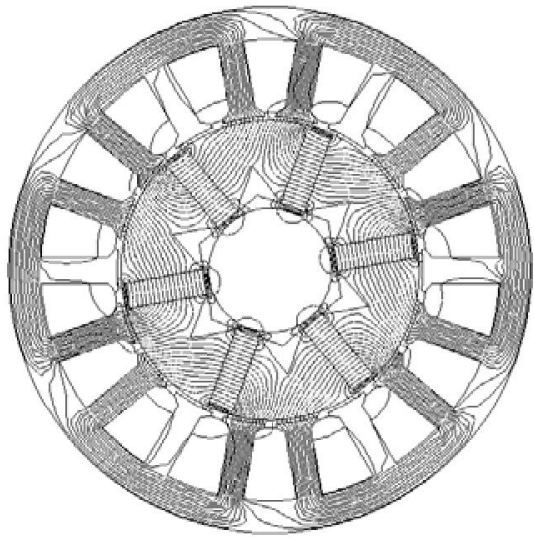

(b) Rated load, $i_{d}=0 \mathrm{~A}, i_{q}=4 \mathrm{~A}$.

Fig. 1. Magnetic field distributions for BLAC motor equipped with an interior permanent magnet rotor. 


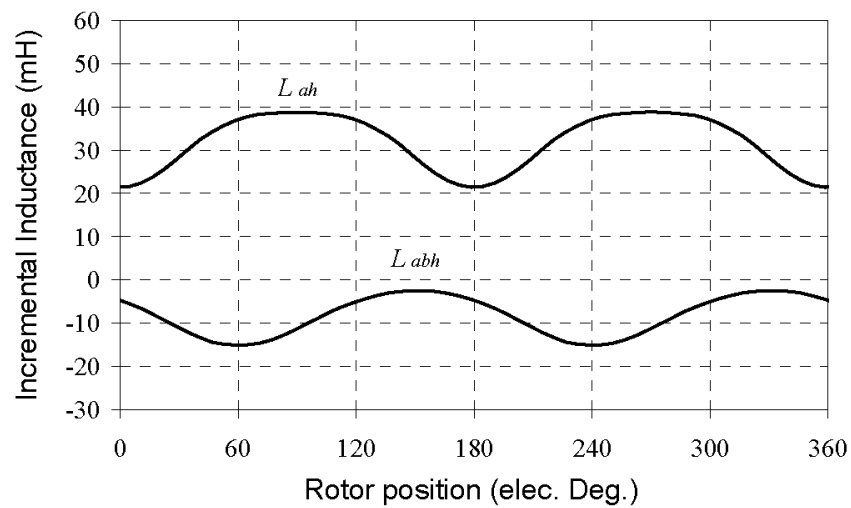

(a) Incremental phase self- and mutual-inductances

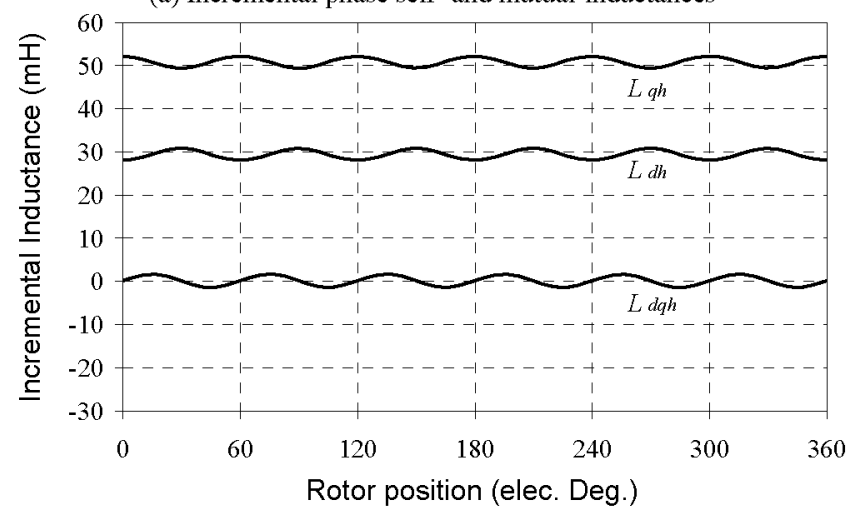

(b) Incremental $d q$-axis inductances

Fig. 2. Incremental inductances on no-load, $i_{d}=0 \mathrm{~A}, i_{q}=0 \mathrm{~A}$.

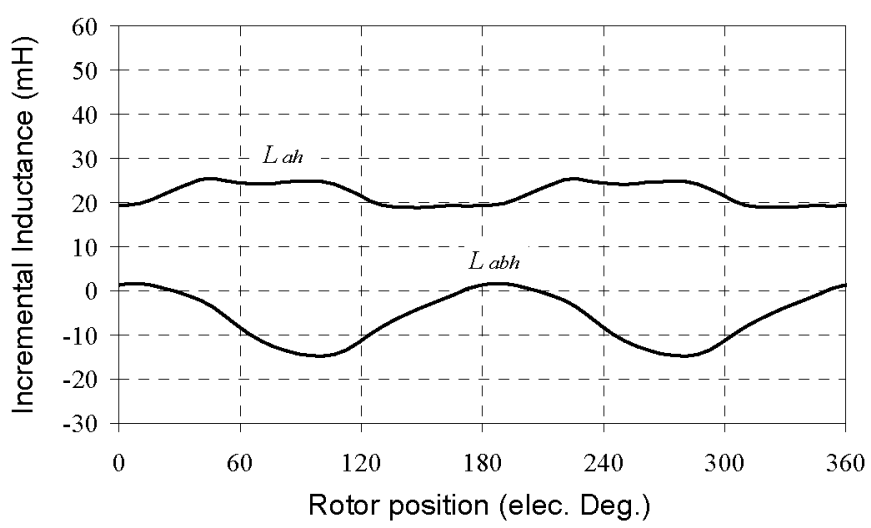

(a) Incremental phase self- and mutual-inductances

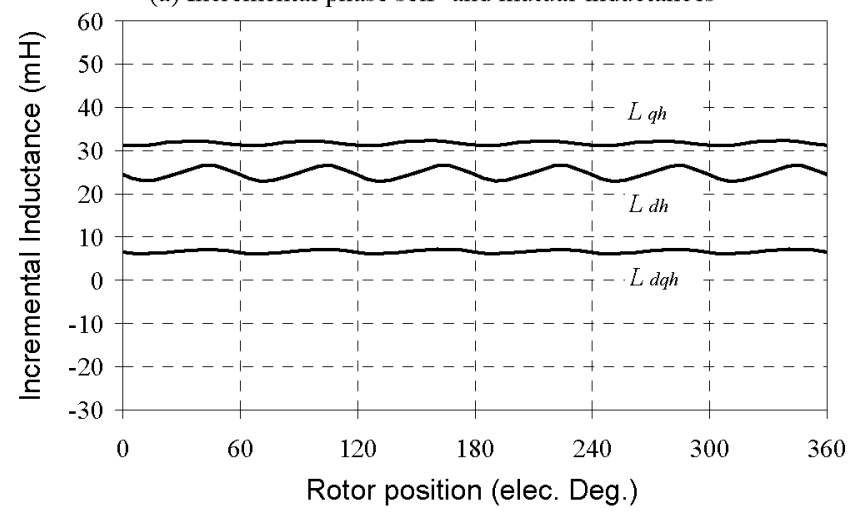

(b) Incremental $d q$-axis inductances

Fig. 3. Incremental inductances on full-load, $i_{d}=0 \mathrm{~A}, i_{q}=4 \mathrm{~A}$.
As $L_{a h}$ and $L_{a b h}$ in Figs. 2(a) and 3(a) vary periodically with the rotor position, $\theta_{r}$, they can be expressed approximately as a Fourier series, i.e.:

$$
\left\{\begin{array}{l}
L_{a h}\left(\theta_{r}\right)=a_{s 0}+\sum_{k=1,2,3, \ldots}\left(a_{s k} \cos k \theta_{r}+b_{s k} \sin k \theta_{r}\right) \\
L_{a b h}\left(\theta_{r}\right)=a_{m 0}+\sum_{k=1,2,3, \ldots}\left(a_{m k} \cos k \theta_{r}+b_{m k} \sin k \theta_{r}\right)
\end{array}\right.
$$

where $a_{s 0}, a_{m 0}, a_{s k}, b_{s k}, a_{m k}$, and $b_{m k}$ are the amplitudes of the DC terms and the $k$ th-order terms of the Fourier series, respectively. Since the amplitude of the high order harmonics in $L_{a h}$ and $L_{a b h}$ is relatively small, only terms up to $k=8$ are considered and transformed from 3-phase to $d q$-values using (6) and (7). The average values of $L_{d h}, L_{q h}, L_{d q h}$ and $L_{d q h}$ are calculated from:

$\left\{\begin{array}{l}L_{d h}=\left(a_{s 0}-a_{m 0}\right)+\left(a_{s 2} / 2+a_{m 2}\right) \\ L_{q h}=\left(a_{s 0}-a_{m 0}\right)-\left(a_{s 2} / 2+a_{m 2}\right) \\ L_{d q h}=L_{q d h}=-\left(b_{s 2} / 2+b_{m 2}\right)\end{array}\right.$

As well be evident from (9), the saliency which results in a BLAC motor equipped with an interior magnet rotor, $L_{d h} \neq L_{q h}$, is caused by 2 nd order co-sine terms, $a_{s 2}, a_{m 2}$, in the $L_{a h}$ and $L_{a b h}$ waveforms, which are considered in [10]. The cross-coupling effect is caused by 2 nd order sine terms, $b_{s 2}, b_{m 2}$, in the $L_{a h}$ and $L_{a b h}$ waveforms, which are usually neglected [10]. In subsequent equations, $L_{q d h}$ is written as $L_{d q h}$. It can also be shown that the 5 th and 7 th order terms in $L_{a h}$ and $L_{a b h}$, i.e., $a_{s 5}$, $b_{s 5}, a_{m 5}, b_{m 5}, a_{s 7}, b_{s 7}, a_{m 7}$, and $b_{m 7}$, cause the variation of $L_{d h}, L_{q h}$, and $L_{d q h}$ with rotor position every 60 elec. deg. Other order harmonics in $L_{a h}$ and $L_{a b h}$ do not appear in $L_{d h}, L_{q h}$ and $L_{d q h}$, as a result of (6).

Although the $d$ - and $q$-axis incremental inductances can be determined by transforming the waveforms of the incremental phase self- and mutual-inductances, $L_{a h}$, and $L_{a b h}$, into the $d q$-axis reference frame, this requires the flux-linkage, $\psi_{a}$, of phase $a$ to be calculated for various $d$ - and $q$ - axis currents and rotor positions, which is time consuming. To reduce the finite element calculation time, the incremental $d$ - and $q$-axis inductances can be calculated directly from $d$ - and $q$ - axis flux-linkages by applying appropriate $d$ - and $q$-axis currents in the finite element analysis, equation (11). Results calculated directly in this way are shown in Fig. 4.

$$
\left\{\begin{array}{l}
L_{d h}=\left[\psi_{d}\left(i_{d}+\Delta i_{d}, i_{q}, \Phi_{m}\right)-\psi_{d}\left(i_{d}, i_{q}, \Phi_{m}\right)\right] / \Delta i_{d} \\
L_{q h}=\left[\psi_{q}\left(i_{d}, i_{q}+\Delta i_{q}, \Phi_{m}\right)-\psi_{q}\left(i_{d}, i_{q}, \Phi_{m}\right)\right] / \Delta i_{q} \\
L_{d q h}=\left[\psi_{d}\left(i_{d}, i_{q}+\Delta i_{q}, \Phi_{m}\right)-\psi_{d}\left(i_{d}, i_{q}, \Phi_{m}\right)\right] / \Delta i_{q} \\
L_{q d h}=\left[\psi_{q}\left(i_{d}+\Delta i_{d}, i_{q}, \Phi_{m}\right)-\psi_{q}\left(i_{d}, i_{q}, \Phi_{m}\right)\right] / \Delta i_{d}
\end{array}\right.
$$

As will be seen from Fig.4, which are average values for various $d$ - and $q$-axis currents, $i_{d}$ and $i_{q}$, the $d$ - and $q$-axis incremental self- and mutual-inductances, $L_{d h}, L_{q h}, L_{d q h}$, vary with the $d$ - and $q$ - axis currents because of saturation. For the BLAC motor under consideration, Fig. 1, $L_{d h} L_{q h}$ and $L_{d q h}$ are 
$25 \mathrm{mH}, 32 \mathrm{mH}$ and $-7 \mathrm{mH}$, respectively, when $i_{d}=0 \mathrm{~A}$ and $i_{q}=4 \mathrm{~A}$. Clearly, since the magnitude of $L_{d q h}$ is comparable with that of $L_{d h}$ and $L_{q h}$ its influence cannot be neglected in the high frequency voltage equations.

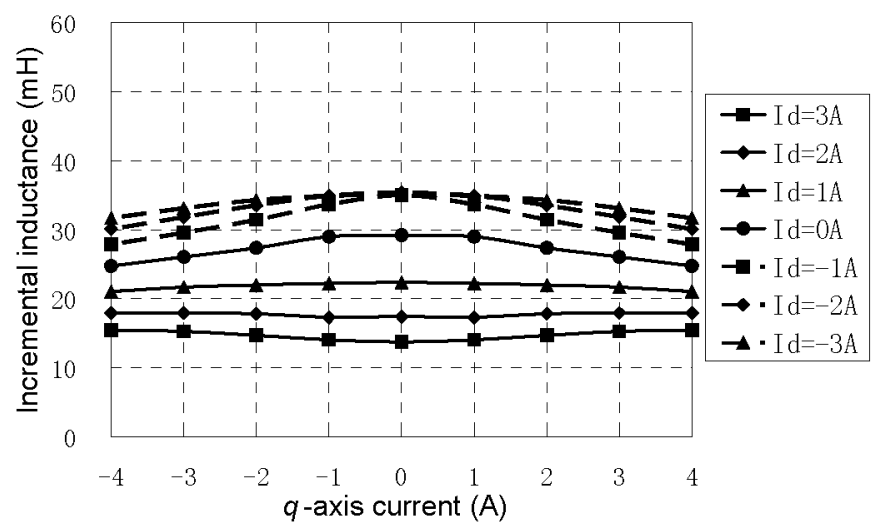

(a) $d$-axis incremental inductance, $L_{d h}$.

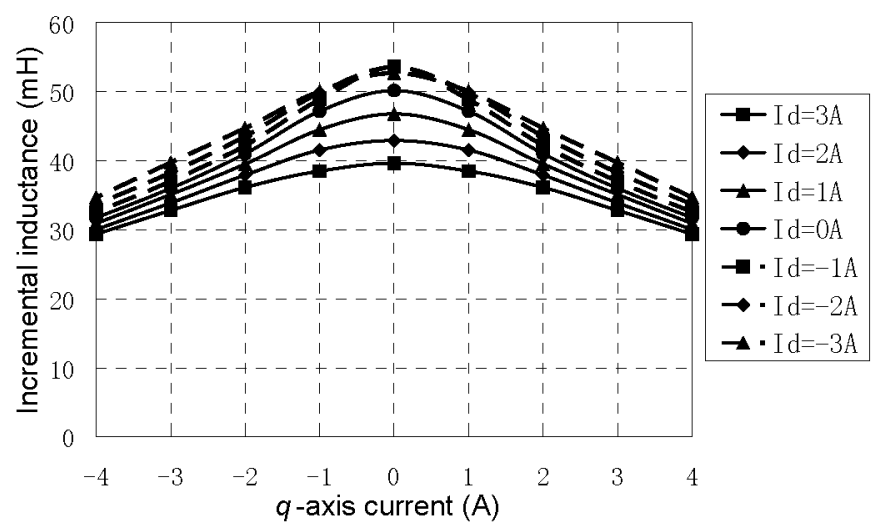

(b) $q$-axis incremental inductance, $L_{q h}$.

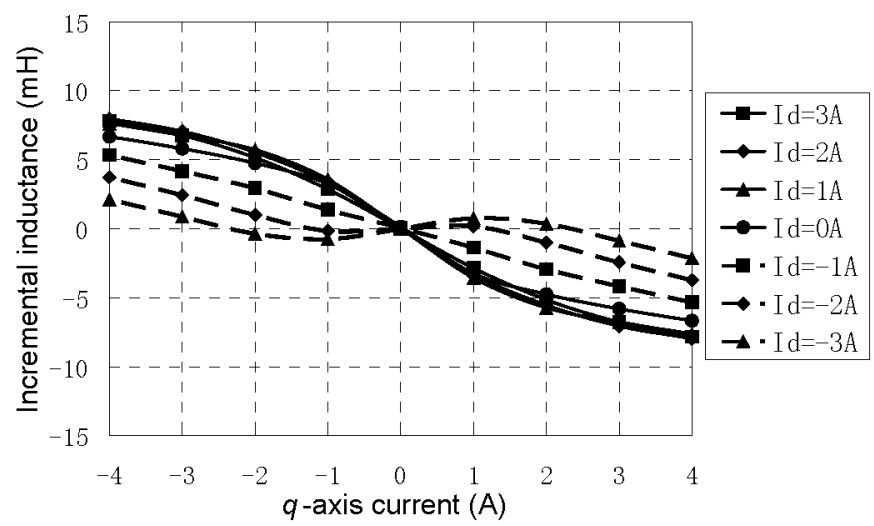

(c) $d q$-axis mutual incremental inductance, $L_{d q h}=L_{q d h \text {. }}$.

Fig. 4. Variation of incremental $d q$-axis self- and mutual-inductances with $d$ and $q$-axis currents.

\section{ANALYSis of Rotor Position ERror CAUSED BY Cross-COUPLing}

As the actual rotor position, $\theta_{r}$, cannot be deduced precisely from the high frequency sensorless position estimation, the reference frame for the high frequency equation (4) is transformed into the estimated rotor position, $\theta_{r}^{e}$, i.e.:

$$
\begin{aligned}
& {\left[\begin{array}{c}
v_{d h}^{e} \\
v_{q h}^{e}
\end{array}\right]=T(\Delta \theta)\left[\begin{array}{l}
v_{d h} \\
v_{q h}
\end{array}\right]=T(\Delta \theta)\left[\begin{array}{cc}
L_{d h} & L_{d q h} \\
L_{d q h} & Z_{q h}
\end{array}\right] T^{-1}(\Delta \theta) \cdot p\left[\begin{array}{c}
i_{d h}^{e} \\
i_{q h}^{e}
\end{array}\right]} \\
& =\left[\begin{array}{cc}
L_{a v g}-\hat{L}_{d i f} \cos \left(2 \Delta \theta+\theta_{m}\right) & \hat{L}_{d i f} \sin \left(2 \Delta \theta+\theta_{m}\right) \\
\hat{L}_{d i f} \sin \left(2 \Delta \theta+\theta_{m}\right) & L_{a v g}+\hat{L}_{d f f} \cos \left(2 \Delta \theta+\theta_{m}\right)
\end{array}\right] p\left[\begin{array}{c}
i_{d h}^{e} \\
i_{q h}^{e}
\end{array}\right]
\end{aligned}
$$

where $\Delta \theta=\theta_{r}{ }^{e}-\theta_{r}$ is the error in the estimated rotor position, and

$$
\begin{aligned}
& T(\Delta \theta)=\left[\begin{array}{cc}
\cos (\Delta \theta) & \sin (\Delta \theta) \\
-\sin (\Delta \theta) & \cos (\Delta \theta)
\end{array}\right] \\
& L_{a v g}=\left(L_{q h}+L_{d h}\right) / 2, \quad L_{d i f}=\left(L_{q h}-L_{d h}\right) / 2 \\
& \theta_{m}=\arctan \left(L_{d q h} / L_{d i f}\right), \quad \hat{L}_{d i f}=\sqrt{L_{d i f}^{2}+L_{d q h}^{2}}
\end{aligned}
$$

Since the high frequency sinusoidal voltage, $v_{\text {sig }}$, is applied to the estimated $d$-axis, i.e., $v_{d h}^{e}=v_{s i g}, v_{q h}{ }^{e}=0$, (12) becomes:

$$
\left[\begin{array}{c}
v_{s i g} \\
0
\end{array}\right]=\left[\begin{array}{cc}
L_{a v g}-\hat{L}_{d i f} \cos \left(2 \Delta \theta+\theta_{m}\right) & \hat{L}_{d i f} \sin \left(2 \Delta \theta+\theta_{m}\right) \\
\hat{L}_{d i f} \sin \left(2 \Delta \theta+\theta_{m}\right) & L_{a v g}+\hat{L}_{d i f} \cos \left(2 \Delta \theta+\theta_{m}\right)
\end{array}\right] p\left[\begin{array}{c}
i_{d h}^{e} \\
i_{q h}^{e}
\end{array}\right]
$$

The resulting $d$-and $q$-axis high frequency currents in the estimated reference frame are obtained by solving (14):

$$
\left\{\begin{array}{l}
i_{d h}^{e}=\frac{v_{\text {sig }}}{p\left(L_{\text {avg }}^{2}-\hat{L}_{d i f}^{2}\right)}\left[L_{\text {avg }}+\hat{L}_{d i f} \cos \left(2 \Delta \theta+\theta_{m}\right)\right] \\
i_{q h}^{e}=-\frac{v_{\text {sig }}}{p\left(L_{\text {avg }}^{2}-\hat{L}_{d i f}^{2}\right)} \hat{L}_{d i f} \sin \left(2 \Delta \theta+\theta_{m}\right)
\end{array}\right.
$$

Thus, if the high frequency component in the $q$-axis current is controlled to be zero, i.e. $i_{q h}{ }^{e}=0$, as was in the conventional signal injection based sensorless schemes [6], an error exists in the estimated rotor position as a result of the incremental mutual inductance, $L_{d q h}$, which exists between $d$ - and $q$-axes. The error is given by:

$$
\Delta \theta=-\frac{\theta_{m}}{2}=\frac{1}{2} \arctan \left(\frac{2 L_{d q h}}{L_{d h}-L_{q h}}\right)
$$

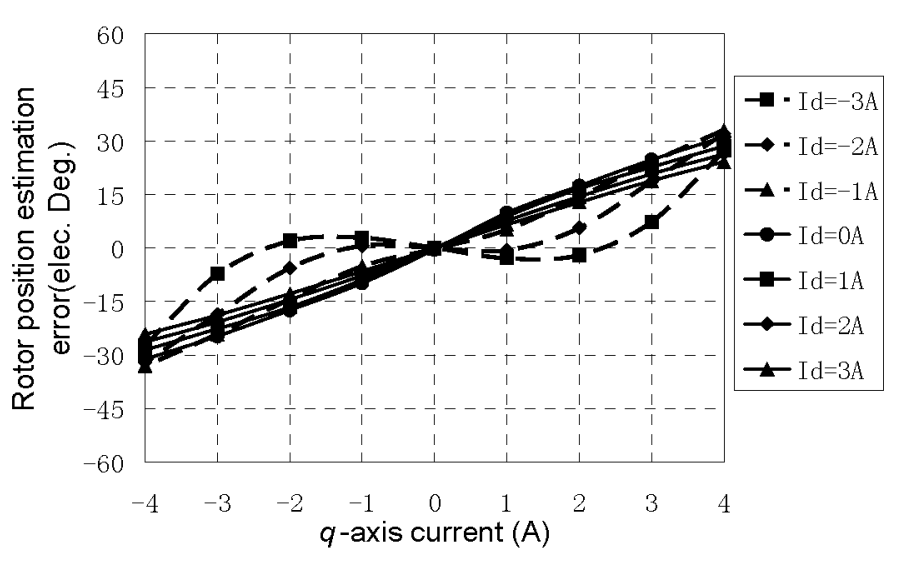

(a) Finite element predicted error, $K \approx 7.5 \%$ A. 


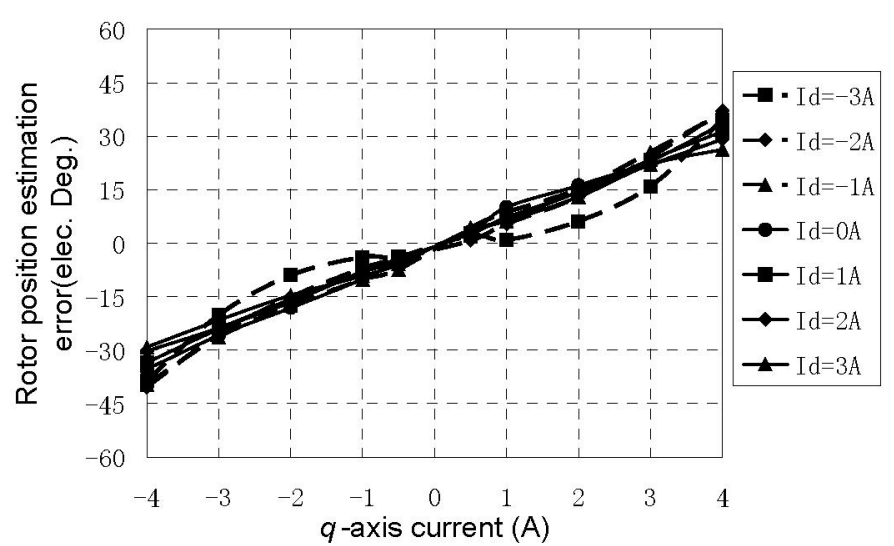

(b) Directly measured error, $K_{F} \approx 8.0^{\circ} / \mathrm{A}$

Fig. 5. Comparison of predicted and measured rotor position estimation error for various $d$ - and $q$-axis currents.

Clearly, the error in the estimated rotor position will only be zero when $L_{d q h}=0$. The stronger the cross-coupling between the $d$ - and $q$-axes, the larger will be the error in the estimated rotor position. For the BLAC motor under consideration, the variation of the predicted error with the $d$ - and $q$-axis currents is shown in Fig.5(a), the predictions being obtained by employing the finite element calculated incremental inductances, Fig. 4, in (16).

The error in the estimated rotor position has also been measured by driving the BLAC motor with the actual rotor position obtained from a precision encoder, so that $i_{d}{ }^{e}=i_{d}$, and $i_{q}{ }^{e}=i_{q}$. The high frequency voltage was injected into the estimated $d$-axis, and the estimated high frequency $q$-axis current, $i_{q h}{ }^{e}$, was forced to zero by adjusting the estimated rotor position, $\theta_{r}^{e}$. The directly measured rotor position estimation error is shown in Fig. 5(b), which compares well with the predicted results shown in Fig. 5(a).

\section{Compensation of Rotor Position ERror due to Cross-Coupling AND COMPARISON WITH CONVENTIONAL METHOD}

The error in the estimated rotor position can be compensated for by either employing (16) or using the results shown in Fig. 5. However, from both the predicted and measured results shown in Fig. 5, it can be seen that the error in estimated rotor position is approximately proportional to the $q$-axis current, i.e. $\Delta \theta \approx K_{r} i_{q}$. Thus, the error can simply be compensated for according to the q-axis current, $i_{q}$, by applying a compensation factor, $K_{r}$. This significantly simplifies the implementation of an error compensation scheme.

The proposed sensorless control scheme is shown in Fig. 6, and the parameters of the interior permanent magnet motor, whose incremental inductance characteristics were shown in Figs. 4 and 5, are given in Table I.

The control strategy is implemented on a TMS320C31 DSP, together with a PIC18F4431 MCU, which serves as the PWM generator and the encoder interface. The frequencies of the $\mathrm{AD}$ sampling, the speed control loop, and the PWM are all set to $5 \mathrm{kHz}$, and the injected signal is $35 \mathrm{~V}, 330 \mathrm{~Hz}$. The actual rotor position, $\theta_{r}$, is obtained from a 1024 pulse-per-revolution encoder, which is used as a reference for the estimated rotor position $\theta_{r}^{e}$. The rotor position error compensation factor, $K_{r}$, was $K_{r}=8.0 \%$, as obtained from the experimental results given in Fig. 5(b).

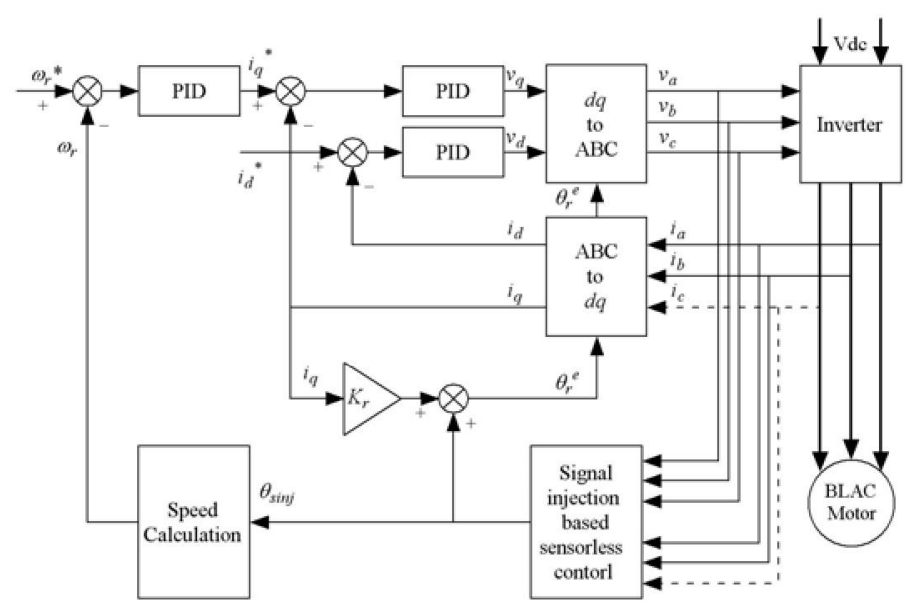

Fig. 6. Signal injection sensorless control with compensation for rotor position error due to cross-coupling.

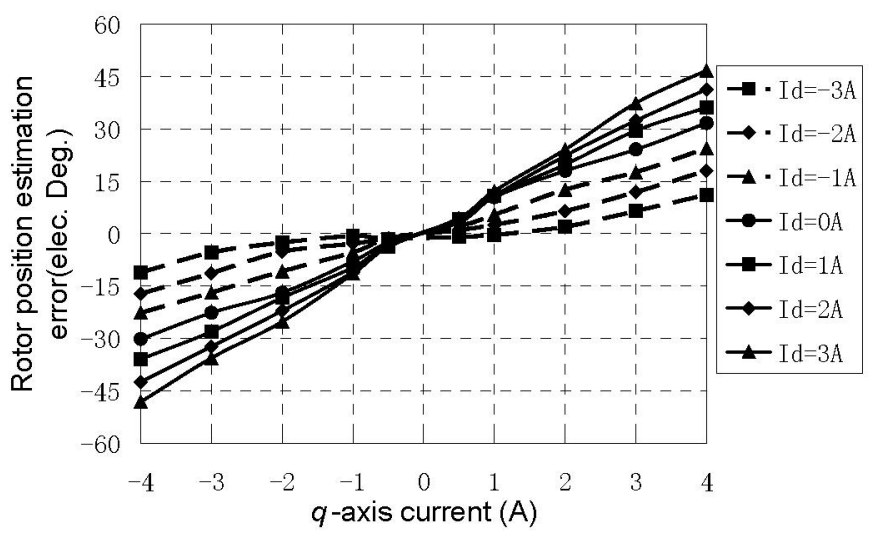

(a) Conventional method, $\operatorname{RMS}\left(\theta_{r}{ }^{e}-\theta_{r}\right)=21.1^{\circ}$

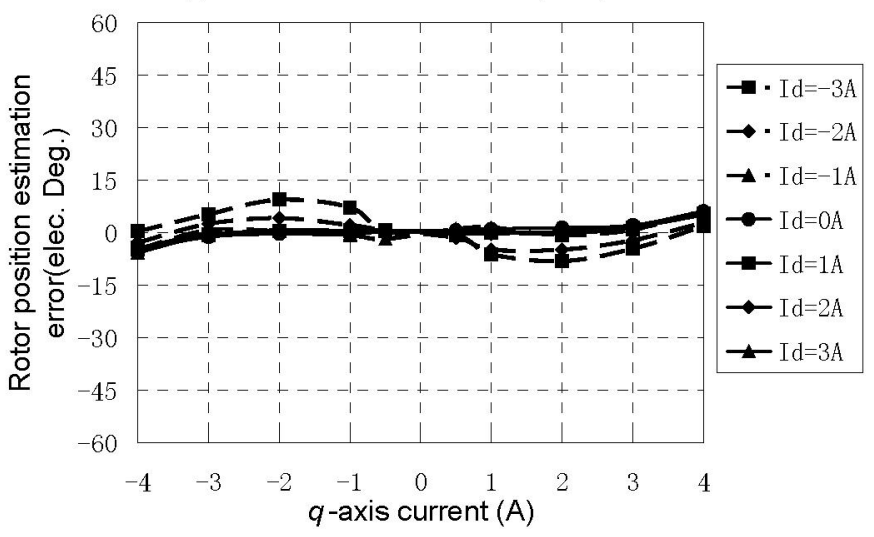

(b) Proposed method, $\operatorname{RMS}\left(\theta_{r}^{e}-\theta_{r}\right)=3.2^{\circ}$

Fig. 7. Measured rotor position estimation error with conventional and proposed signal injection based sensorless methods. 
TABLE I

SPECIFICATION OF BLAC MOTOR

\begin{tabular}{lc}
\hline Number of pole-pairs & 3 \\
Rated speed & $1000 \mathrm{rpm}$ \\
Rated torque & $4.0 \mathrm{Nm}$ \\
Rated phase voltage (peak) & $158 \mathrm{~V}$ \\
Rated phase current (peak) & $4.0 \mathrm{~A}$ \\
Phase resistance $R_{s}$ & $6.0 \Omega$
\end{tabular}

Fig. 7 compares the measured steady-state error in the estimated rotor position for various $d$ - and $q$-axis currents, $i_{d}{ }^{e}$ and $i_{q}{ }^{e}$, when the estimated rotor position is used for position feedback. With conventional signal injection based sensorless control, Fig. 7(a), the rotor position estimation error increases with both the magnitude of $i_{q}$ and increasing positive values of $i_{d}$, since the magnetic circuit then becomes more heavily saturated and the influence of $d q$-axis cross-coupling becomes more significant. For example, the error increases to $45^{\circ}$ when $i_{d}=3 \mathrm{~A}, i_{q}=4 \mathrm{~A}$, while the root mean square (RMS) error in Fig. 7 (a) is $21.1^{\circ}$. However, when the proposed error compensation method is applied, the RMS rotor position estimation error is reduced to only $3.2^{\circ}$, Fig. 7(b).

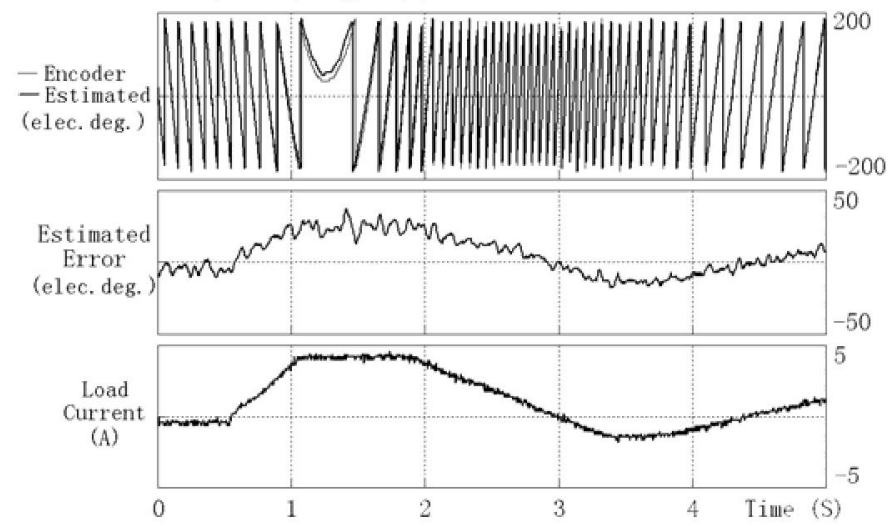

(a) Conventional method

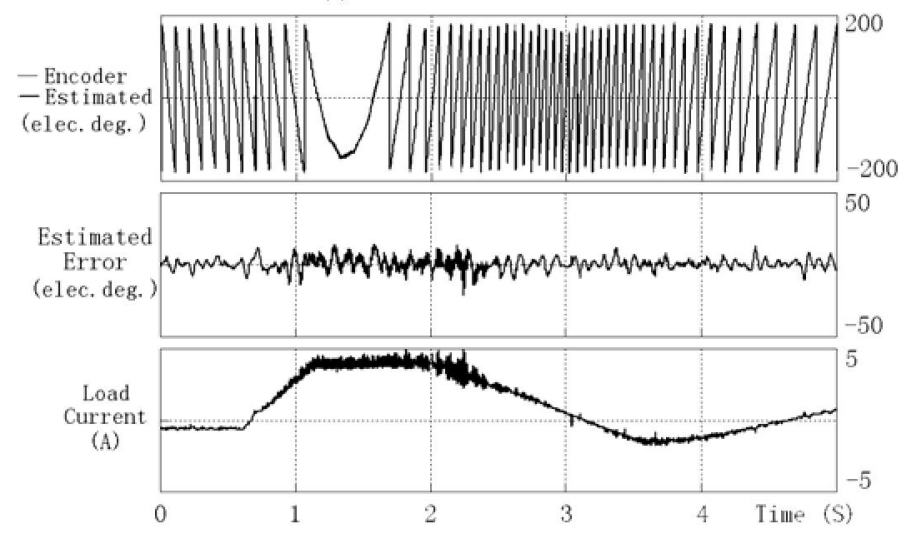

(b) Proposed method

Fig. 8. Step speed response of signal injection based sensorless operation (speed command: $\pm 10 \mathrm{~Hz}$, and $i_{d}=0$ ).

Fig. 8 compares the estimated and actual rotor position when the estimated rotor position is used for position feedback and the rotor speed command is changed from $-10 \mathrm{~Hz}$ to $+10 \mathrm{~Hz}$, i.e., $-200 \mathrm{rpm}$ to $+200 \mathrm{rpm}$. As will be seen in Fig. 8(a), when the conventional signal injection based sensorless scheme is employed, the estimated rotor position error increases significantly with the load current, and is $25^{\circ}$ when $i_{q}=4 \mathrm{~A}$. By applying the proposed error correction method this reduces to $5^{\circ}$, Fig. 8(b)

\section{Conclusions}

Finite element analysis and measurements have shown that the neglect of cross-coupling between the d- and q-axes of a BLAC motor which results due to magnetic saturation, may lead to significant errors in the rotor position estimation when signal injection based sensorless control is employed. However, by applying a simple error correction method, a significant improvement in the accuracy of the rotor position estimation can be achieved.

\section{REFERENCES}

[1] S. Ogasawara, and H. Akagi, "Implementation and position control performance of a position-sensorless IPM motor drive system based on magnetic saliency," IEEE Trans. Industry Applications, vol.34, no. 4, pp. 806-812, July-Aug. 1998.

[2] M. J. Corley, and R. D. Lorenz, "Rotor position and velocity estimation for a salient-pole permanent magnet synchronous machine at standstill and high speed," IEEE Trans. Industry Applications, vol.34, no. 4, pp 784-789, July/August 1998.

[3] T. Aihara, A. Toba, T. Yanase, A. Mashimo, and K. Endo, "Sensorless torque control of salient-pole synchronous motor at zero-speed operation," IEEE Trans. Power Electronics, vol. 14, no. 1, pp.202-208, Jan. 1999.

[4] J.I. Ha, K. Ide, T. Sawa, and S.K. Sul, "Sensorless rotor position estimation of an interior permanent-magnet motor from initial states", IEEE Trans. Industry Applications, vol. 39, no. 3, pp.761-767, May-June 2003.

[5] H. Kim, K.K. Huh, and R.D. Lorenz, "A novel method for initial rotor position estimation for IPM synchronous machine drives," IEEE Trans. Industry Applications, vol. 40, no. 5, pp. 1369-1378, September/October 2004.

[6] J.H. Jang, S.K. Sul, J.I. Ha, K. Ide, and M. Sawamura, "Sensorless drive of surface-mounted permanent-magnet motor by high-frequency signal injection based on magnetic saliency," IEEE Trans. Industry Applications, vol. 39, no. 4, pp. 1031-1039, July-Aug. 2003.

[7] P. Guglielmi, M. Pastorelli, A. Vagati, "Cross saturation effects in IPM motors and related impact on zero-speed sensorless control," Conf. Rec. IEEE-IAS Annu. Meeting, vol. 4, pp. 2546-2552, 2005.

[8] N. Bianchi, S. Bolognani, "Influence of rotor geometry of an interior PM motor on sensorless control feasibility," Conf. Rec. IEEE-IAS Annu. Meeting, vol. 4, pp. 2553-2560, 2005

[9] B. Stumberger, G. Stumberger, D. Dolinar, A. Hamler, M. Trlep, "Envaluation of saturation and cross-magnetization effects in interior permanent-magnet synchronous motor," IEEE Trans. Industry Applications, vol. 39, no. 5, pp. 1264-1271, September/October 2003.

[10] A. E. Fitzgerald, Charles Kingsley, Jr., Stephen D. Umans, "Electric Machinery, $5^{\text {th }}$ Edition", McGraw-Hill Book, 1992. 